Research Article

\title{
Control System Design for 16/6/8 Double-Stator Bearingless Switched Reluctance Motor
}

\author{
Chuanyu Sun $\left(\mathbb{D},{ }^{1}\right.$ Hang Yang, ${ }^{2}$ Shangke Han, ${ }^{2}$ Hongchang Ding, ${ }^{1}$ Jiaqing Li, ${ }^{1}$ and Ning Han ${ }^{1}$ \\ ${ }^{1}$ College of Mechanical and Electronic Engineering, Shandong University of Science and Technology, Qingdao 266590, China \\ ${ }^{2}$ College of Ocean Science and Engineering, Shandong University of Science and Technology, Qingdao 266590, China
}

Correspondence should be addressed to Chuanyu Sun; 13708983820@163.com

Received 15 June 2021; Revised 17 August 2021; Accepted 19 August 2021; Published 31 August 2021

Academic Editor: M Syed Ali

Copyright ( 2021 Chuanyu Sun et al. This is an open access article distributed under the Creative Commons Attribution License, which permits unrestricted use, distribution, and reproduction in any medium, provided the original work is properly cited.

The 16/6/8 double-stator bearingless switched reluctance motor (DSBSRM) is used as the object of study in this paper. To solve the problem of torque and levitation force ripples in this motor, a control system direct force control (DFC) and direct instantaneous torque control (DITC) based on the torque sharing function (TSF) are proposed. With the strong nonlinearity and approximation capability of radial basis function neural networks, the torque and levitation force observer are designed. The observed torque and levitation forces are used as feedback for the internal loop control, which is combined with the external loop control to make a double closed-loop control. In order to further improve the output torque and system robustness and suppress the torque ripple in steady-state process, the motor winding method is optimized and a set of switching angles is added on the basis of TSF. The simulation results verify the effectiveness and superiority of the proposed control method. It effectively suppresses speed ripple and reduces torque and levitation force fluctuations and rotor radial displacement jitter.

\section{Introduction}

With the development of modern industry, the performance requirements of motors are becoming higher and higher. The traditional motor uses mechanical bearings, so the bearing has high mechanical wear, works less efficiently, and has a low life at high speeds. In order to overcome the disadvantages of mechanical bearing, scholars proposed the bearingless switched reluctance motor (BSRM) $[1,2]$. It not only has the advantages of simple structure, good speed regulation performance, and high mechanical strength of switched reluctance motor (SRM), but also solves the problem of mechanical bearings. Due to the longer motor life, the absence of mechanical friction, and the lack of lubrication, it is used in a wide range of applications [3,4]. However, BSRM has strong coupling and fluctuation problems. To solve these problems, scholars at home and abroad have conducted a lot of research mainly in two aspects: structure and control algorithm.

Based on the structural characteristics, four types can be distinguished: mixed stator tooth structure, wide rotor tooth structure, double-stator structure, and composite rotor structure [5-11]. The dual stator structure, with the outer stator winding providing the torque and the inner stator winding providing the levitation, provides better decoupling and easier control by separating the torque and levitation force magnetic circuits [10, 12-14]. Current square wave control is the main control method, where the winding current is directly regulated by a current hysteresis controller to produce the required torque and levitation force $[13,15]$. However, this method requires complex mathematical model calculations and has large fluctuation of levitation force and torque. At present, there is a hot topic of research in applying the control methods from SRM to BSRM [15-20]. The DTC (direct torque control) and DFC can better suppress torque and levitation force ripples by setting the space voltage vector table reasonably well. They can also improve control accuracy and motor robustness by combining neural networks or superhelix algorithms [15-18]. It was found that DITC is more effective than DTC in suppressing torque ripples. With a limited switching frequency, the DITC improves the operating efficiency of the motor by enabling smoother output torque during phase change $[19,20]$. 
In order to suppress torque and levitation force torque pulsation for $16 / 6 / 8$ DSBSRM [21], this paper proposes a DTC and DFC control system based on RBF. In addition, to increase the output torque, the motor winding is optimized and a set of switching angles is added to the original TSF. Finally simulation verifies the effectiveness and superiority of the control system.

\section{Motor Structure, Operating Principle, and Coupling Analysis}

2.1. Motor Structure and Operating Principle. The structure of the $16 / 6 / 8$ DSBSRM is shown in Figure 1(a), with the outer stator, rotor, and inner stator from outside to inside. The outer stator is a torque stator with 16 teeth, and each tooth is wound with two sets of coils. There are 8 phases and the coils $A 1+, A 1-, A 2+$, and $A 2-$ form phase $A$ in series, as shown in Figure 1(b). The rotor consists of 6 torque teeth, a magnetic isolation frame, and a toroidal core. The torque teeth are set as " $U$ " to increase the output torque. The inner stator is a levitation stator, consisting of 4 permanent magnets and 4 levitation teeth. The permanent magnets are arranged at $45^{\circ}, 135^{\circ}, 225^{\circ}$, and $315^{\circ}$ to provide magnetic pull; the levitation teeth are arranged at $0^{\circ}, 90^{\circ}, 180^{\circ}$, and $270^{\circ}$, and a set of coils are wound. $M+$ and $M$ - coils in series form the control winding of one phase. The control winding and the permanent magnets work together to achieve the stable levitation of the motor.

Figure 2 shows the operating principle of 16/8/6 DSBSRM. As shown in Figure 2(a), when the A-phase winding is energized, two excitation loops are formed between the outer stator teeth and the rotor teeth. Based on the "principle of minimum magnetoresistance", two magnetic pulls which drive the rotor counterclockwise are generated. If the $A \longrightarrow D \longrightarrow G \longrightarrow B \longrightarrow E \longrightarrow H \longrightarrow C \longrightarrow F$-phase winding is energized in turn, the rotor rotates counterclockwise, and if the $F \longrightarrow C \longrightarrow H \longrightarrow E \longrightarrow B \longrightarrow G \longrightarrow D \longrightarrow A$-phase winding is energized, the rotor rotates clockwise.

As shown in Figures 2(a) and 2(b), when the rotor is levitated in the ideal center, the $F_{A 1}$ and $F_{A 2}$ combined torque force is 0 , so the levitation force is provided only by the permanent magnet. Since the four permanent magnets are structured symmetrically, levitation forces provided by permanent magnets $F 1, F 2, F 3$, and $F 4$ will be of the same size and $90^{\circ}$ apart in direction. When the rotor is eccentric in the $-X$ direction, the air gap reluctance corresponding to each magnetic circuit changes, which causes $F_{A 1}, F_{A 2} F 1, F 2$, $F 3$, and F4 combined force to be nonzero. Therefore, the inner stator has a levitation force on the rotor in the $-X$ direction when the $M$-phase winding is not energized. As the $M$-phase winding current gradually increases, the magnetic flux density increases in the $+X$ direction and decreases in $-X$ direction, as shown in Figures 2(a) and 2(c). When the magnetic flux density is greater in the $+X$ direction than in the $-X$ direction, suspending force gradually changes from negative value to positive value, and levitation force is generated in the $+X$ direction. Similarly, levitation force is generated in the $+Y$ direction when $\mathrm{N}+$ and $-\mathrm{N}$ are energized positively. By adjusting the current of the four windings appropriately, the levitation forces can be provided in any direction to satisfy levitation requirements.

2.2. Mathematical Analytical Model. In order to achieve stable levitation and rotation of a bearingless motor, the relationship between torque and levitation force, rotor position angle, and winding current needs to be expressed to clarify the control laws for the phase windings. The virtualwork method is adopted to derive the mathematical model of torque and levitation forces.

As derived in [21], the torque can be expressed as

$$
T_{A}=2 N^{2} i^{2} \mu_{0} h r\left(\frac{c_{1}}{\delta_{1}}+\frac{4 c_{2}}{\pi\left(r \theta-\delta_{1}\right)}\right) .
$$

Magnetic leakage factor $c_{1}=0.2$ and $c_{2}=-3$, when $\theta$ is at $\left[6^{\circ}-7.5^{\circ}\right]$. When $\theta$ is at $\left[7.5^{\circ}-13.5^{\circ}\right], c_{1}=0.925$ and $c_{2}=0.756$. $\delta_{1}$ is the thickness of the air gap between the outer stator and the rotor.

Similarly, ignoring magnetic leakage conditions, we can express $X$ direction suspending force $F_{x}$ as

$$
F_{x}=\frac{\left(\Phi_{\mathrm{PM} 2}+\mu_{0} A \delta_{2} N i\right)^{2}-\left(\Phi_{\mathrm{PM} 1}-\mu_{0} A \delta_{2} N i\right)^{2}}{2 \mu_{0} A}
$$

where $\delta_{2}$ is the thickness of the air gap between the inner stator and the rotor. $x$ is the eccentric displacement in the $X$ direction. $\Phi_{\mathrm{PM} 1}$ is the upper permanent magnet bias magnetic flux, and $\Phi_{\mathrm{PM} 2}$ is the lower permanent magnet bias magnetic flux. $\Phi_{\mathrm{PM} 1}$ and $\Phi_{\mathrm{PM} 2}$ can be expressed as

$$
\begin{aligned}
& \Phi_{\mathrm{PM} 1}=\frac{2 \delta_{2} \mu_{0} A F_{\mathrm{PM}}}{\left(\mu_{0} A R_{\mathrm{PM}}+\delta-x \cos 45^{\circ}\right)\left(2 \delta_{2}-x\right)+2 \delta_{2}\left(\delta_{2}-x\right)}, \\
& \Phi_{\mathrm{PM} 2}=\frac{2 \delta_{2} \mu_{0} A F_{\mathrm{PM}}}{\left(\mu_{0} A R_{\mathrm{PM}}+\delta_{2}+x \cos 45^{\circ}\right)\left(2 \delta_{2}+x\right)+2 \delta_{2}\left(\delta_{2}+x\right)} .
\end{aligned}
$$

2.3. Coupling Analysis. To verify the decoupling performance of the 16/6/8 DSBSRM, a simulation model was built in Maxwell with the motor specific parameters shown in Table 1.

Figure 3 shows the torque and permanent magnet flux density diagram. When the $A$-phase torque winding is energized with $10 \mathrm{~A}\left(I_{A}=10 \mathrm{~A}\right)$, the magnetic separator separates the magnetic field lines generated by the torque winding from the magnetic field lines generated by the permanent magnet, so that the two magnetic field lines do not intersect. It shows that the decoupling effect of torque and levitation force is very good. As shown in Figures 4(b) and $4(\mathrm{c})$, when the levitation winding of phase $M$ is energized with $6 \mathrm{~A}\left(I_{M}=6 \mathrm{~A}\right)$, the magnetic flux density is greater in the $+X$ direction than in the $-X$ direction. As the $M$-phase winding current gradually increases, in the $+X$ direction, the magnetic flux density $X-B$ increases and the levitation force $F_{x}$ gradually increases. However, in the $+Y$ direction, the 


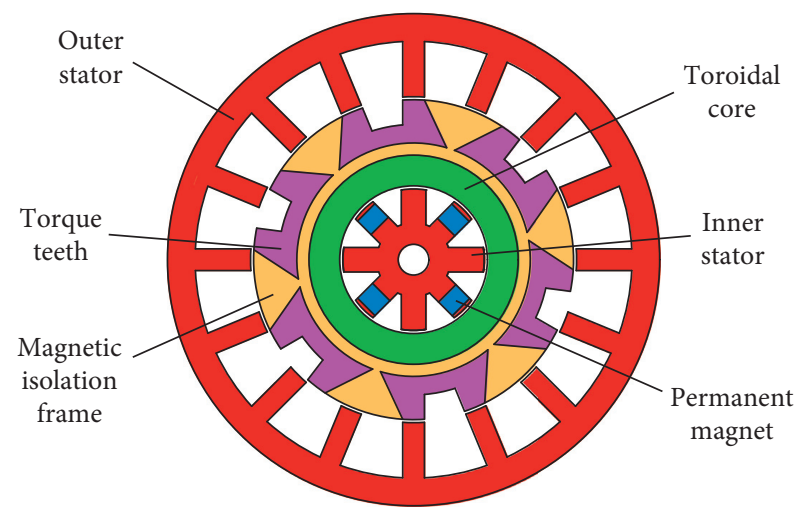

(a)

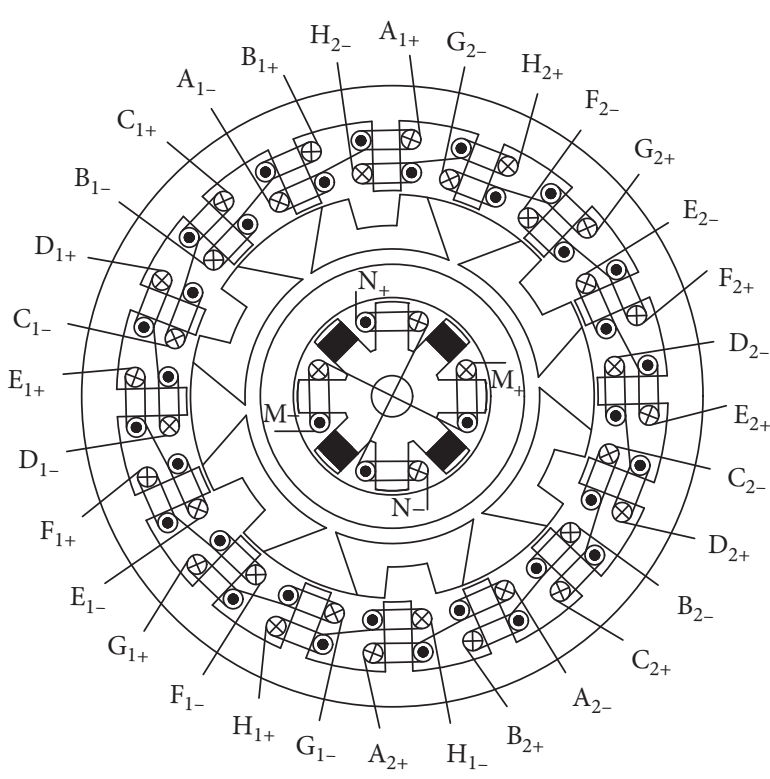

(b)

FIgURE 1: The structure of the DSBSRM: (a) exploded view of 16/8/6 DSBSRM; (b) DSBSRM winding mode.

magnetic flux density $Y-B$ and the levitation force $F_{y}$ remain largely unchanged.

The analysis of Figures 3 and 4 shows that the decoupling between torque and levitation forces works well, as well as the equally good decoupling of levitation forces in $X$ and $Y$. As a result, torque and levitation forces can be controlled separately, and the levitation forces in the $X$ and $Y$ directions can also be controlled separately.

\section{Design of Control System}

According to Section 2.3, the decoupling effect of torque and levitation is very good. Therefore, when the control system of 16/8/6 DSBSRM is designed, the torque control system and levitation control system are designed, respectively.

3.1. Design of Torque Control System. The torque characteristic is analyzed by Maxwell simulation within a rotor period of $60^{\circ}$, as shown in Figure 5. It is found that the torque tends to oscillate and gradually decrease with increasing rotor position angle. Moreover, there are two positive torque zones: $0-15^{\circ}$ and $27-35^{\circ}$. To better understand the two positive torque zones, at the same rotor cycle, the $A$-phase winding and the $H$-phase winding are enabled separately with a current of $10 \mathrm{~A}$. As shown in Figure 6, when the rotor angle is right at $0-15^{\circ}$, the first positive torque region of A-phase intersects with the second positive torque region of $H$ phase. Consequently, when both phase windings are on at the same time, the torque generated by the $H$-phase winding is superimposed on the torque generated by the $A$-phase winding, resulting in an increase in output torque.

In order to make full use of the two positive torque zones of the motor and to improve the operating efficiency of the motor, a TSF-based DITC control method was used. The method can output a specific reference torque by setting the switching angle reasonably and adjusting the torque change rate, so as to achieve smooth commutation and effectively reduce the torque fluctuation $[19,20,22]$.

The TSF includes linear, sine, cosine, cubic, and exponential types. The cosine function is more suitable for nonlinear systems than the linear type and has a smaller copper loss compared to other functions [22]. Therefore, it can suppress torque fluctuations well, and the cosine function is shown as follows:

$$
f_{k}(\theta)= \begin{cases}\frac{1}{2}-\frac{1}{2} \cos \left(\pi \frac{\theta-\theta_{\text {on } 1}}{\theta_{\mathrm{ov}}}\right), & \theta_{\text {on }} \leq \theta<\theta_{\mathrm{on}}+\theta_{\mathrm{ov}}, \\ 1, & \theta_{\mathrm{on}}+\theta_{\mathrm{ov}} \leq \theta<\theta_{\mathrm{off}}, \\ \frac{1}{2}+\frac{1}{2} \cos \left(\pi \frac{\theta-\theta_{\mathrm{off} 1}}{\theta_{\mathrm{ov}}}\right), & \theta_{\text {off }} \leq \theta<\theta_{\text {off }}+\theta_{\mathrm{ov}} \\ 0, & \text { else }\end{cases}
$$

where $\theta$ is the rotor position angle, $\theta_{\text {on }}$ is the turn-on angle, $\theta_{\text {off }}$ is the turn-off angle, and $\theta_{\text {ov }}$ is the phase current commutation overlap angle. The waveform is shown in Figure 7.

Based on the analysis of the torque characteristic curve of the motor, a set of switching angles is added to the traditional cosine function to regulates the on/off of the second positive torque region. The improved TSF is shown as follows: 


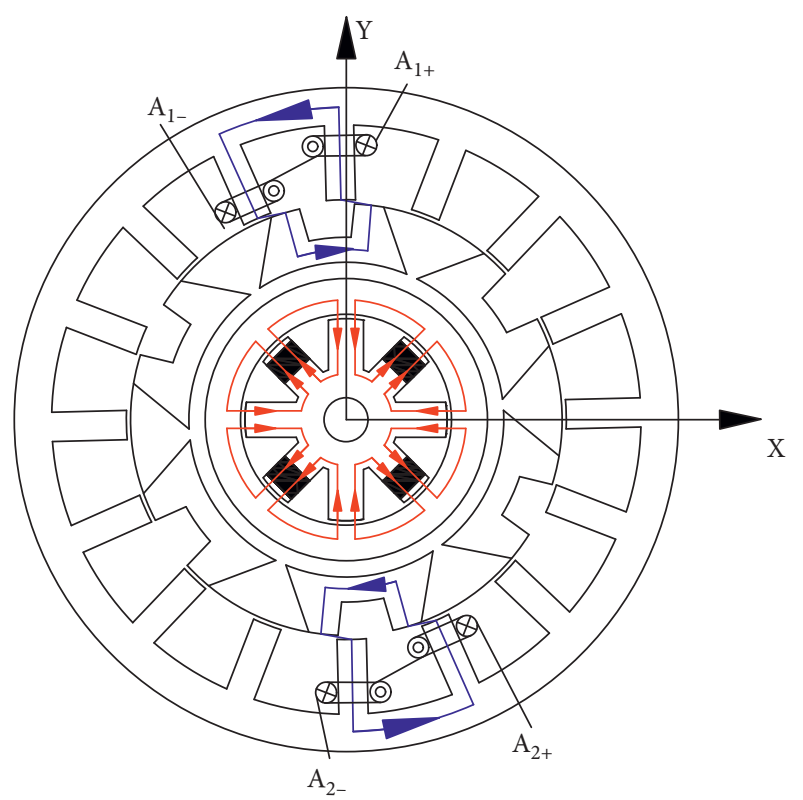

(a)

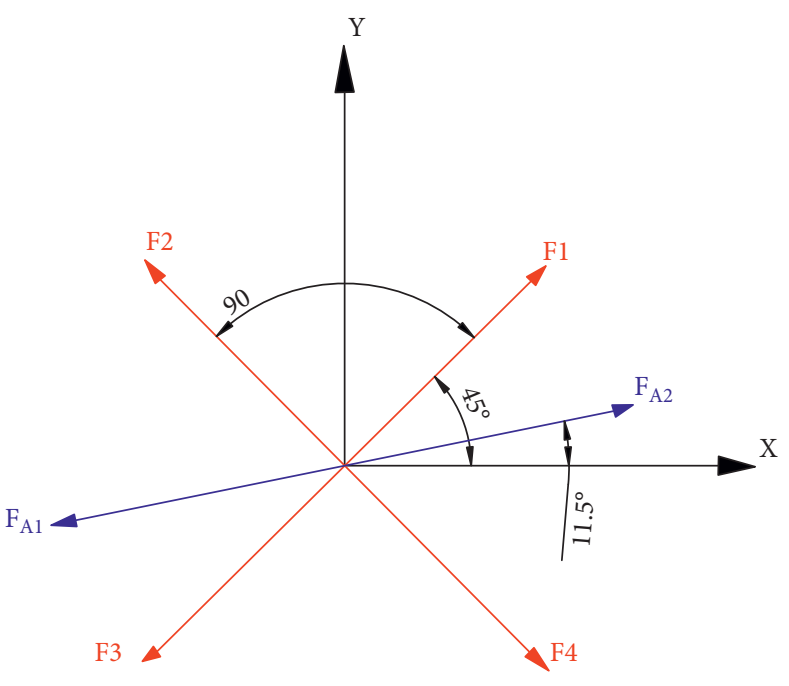

(b)

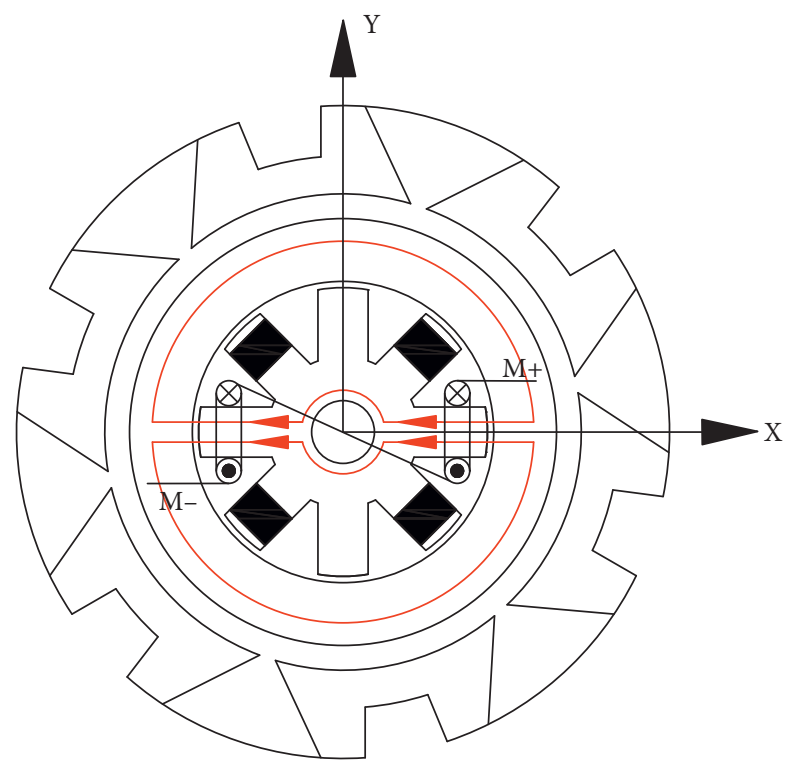

(c)

FIgURE 2: Schematic diagram of motor operation: (a) equivalent magnetic circuit model of torque winding and permanent magnet; (b) force analysis diagram of rotor; (c) equivalent magnetic circuit model of control winding.

TABle 1: Parameters of $16 / 6 / 8$ DSBSRM.

Parameter name

Outer stator outer diameter

Outer stator inner diameter

Rotor outer diameter

Rotor inner diameter

Torque tooth height

Outer diameter of inner stator

Inner stator inner diameter

Motor axial length

External stator tooth pole arc

Protruding pole arc of torque tooth

Torque tooth pole arc

Length of permanent magnet
Parameter value

$80 \mathrm{~mm}$

$53 \mathrm{~mm}$

$52 \mathrm{~mm}$

$24 \mathrm{~mm}$

$7 \mathrm{~mm}$

$23 \mathrm{~mm}$

$5 \mathrm{~mm}$

$80 \mathrm{~mm}$

$7.5^{\circ}$

$7.5^{\circ}$

$30^{\circ}$

$3 \mathrm{~mm}$ 

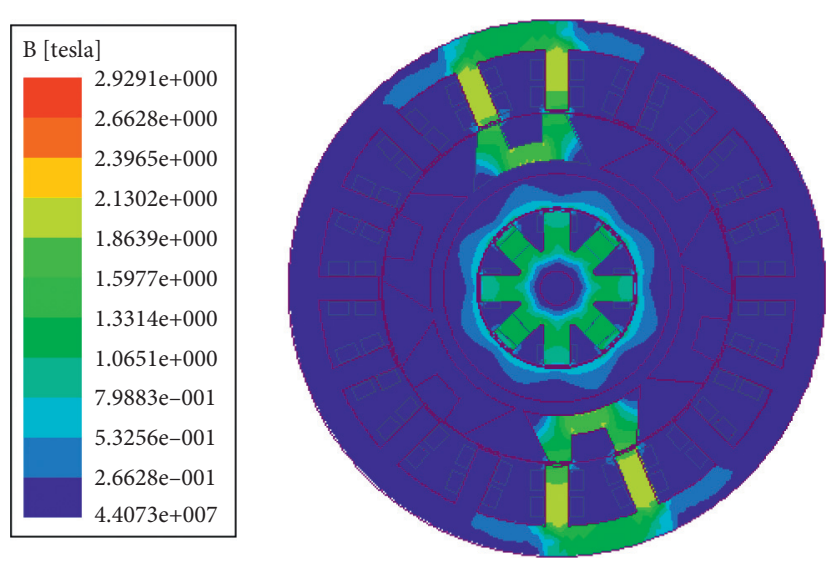

Figure 3: Torque and permanent magnet flux density diagram.

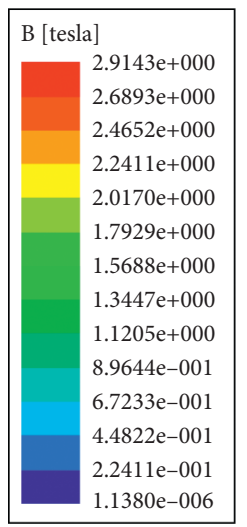

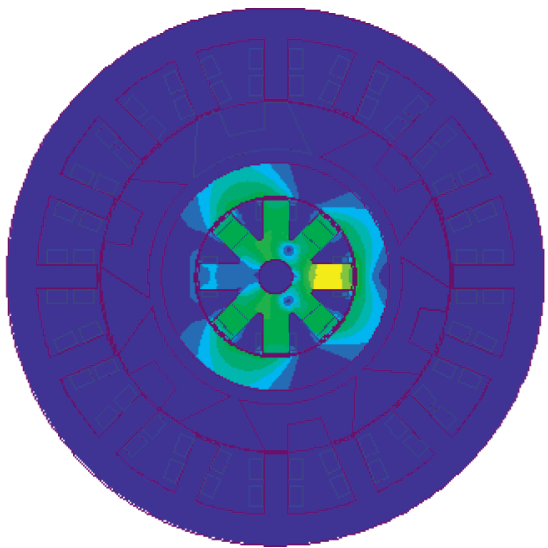

(a)

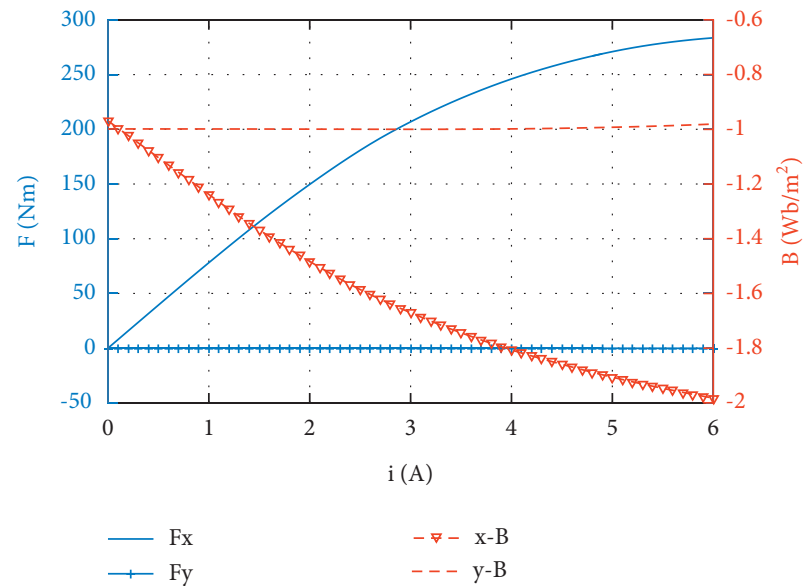

(b)

FIGURE 4: Levitation force coupling analysis diagram: (a) magnetic flux density diagram for levitation force; (b) levitation force and magnetic flux density graphs.

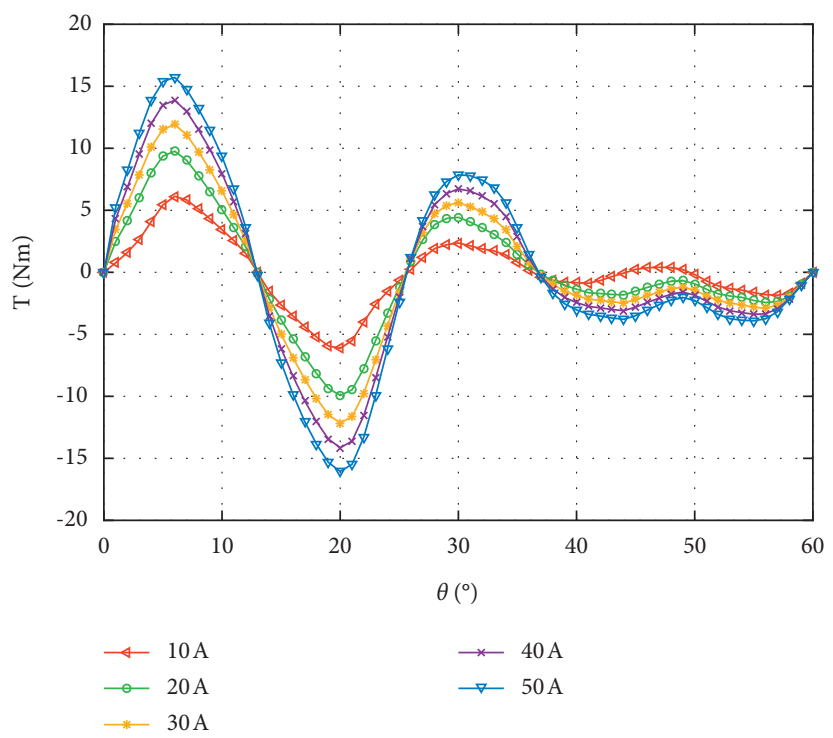

Figure 5: Torque characteristic curve. 


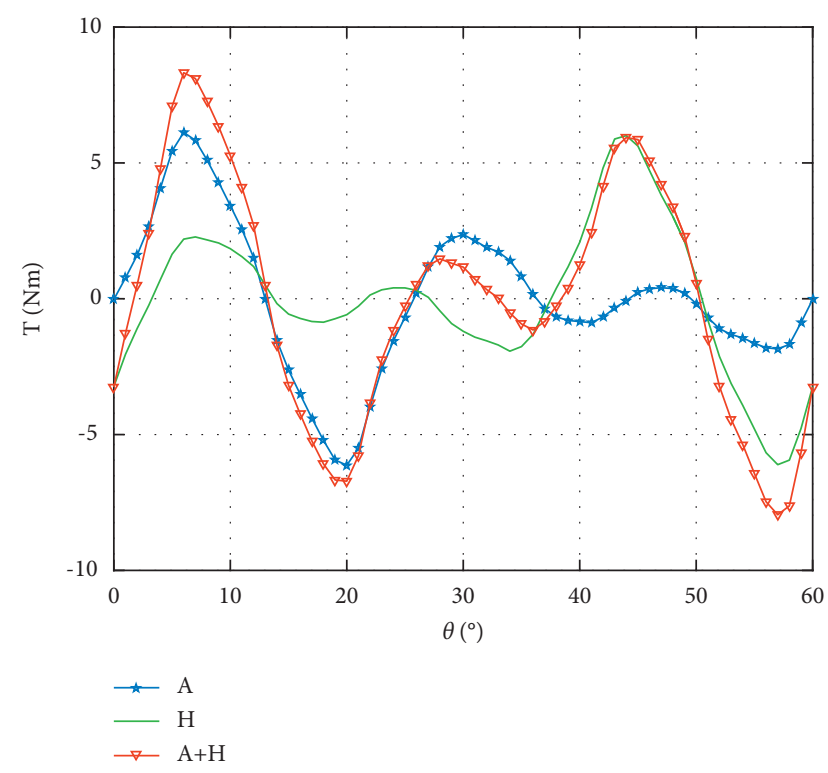

FIgURE 6: Torque superposition curve.

$$
f_{k}(\theta)= \begin{cases}\frac{1}{2}-\frac{1}{2} \cos \left(\pi \frac{\theta-\theta_{\mathrm{on} 1}}{\theta_{\mathrm{ov}}}\right), & \theta_{\mathrm{on} 1} \leq \theta<\theta_{\mathrm{on} 1}+\theta_{\mathrm{ov}} \\ 1, & \theta_{\mathrm{on} 1}+\theta_{\mathrm{ov}} \leq \theta<\theta_{\mathrm{off} 1} \\ \frac{1}{2}+\frac{1}{2} \cos \left(\pi \frac{\theta-\theta_{\mathrm{off} 1}}{\theta_{\mathrm{ov}}}\right), & \theta_{\mathrm{off} 1} \leq \theta<\theta_{\mathrm{off} 1}+\theta_{\mathrm{ov}} \\ \frac{1}{2} \cos \left(\pi \frac{\theta-\theta_{\mathrm{on} 2}}{\theta_{\mathrm{ov}}}\right), & \theta_{\mathrm{on} 2} \leq \theta<\theta_{\mathrm{on} 2}+\theta_{\mathrm{ov}} \\ \frac{1}{2}+\frac{1}{2} \cos \left(\pi \frac{\theta-\theta_{\mathrm{off} 2}}{\theta_{\mathrm{ov}}}\right), & \theta_{\mathrm{off} 2} \leq \theta<\theta_{\mathrm{off} 2}+\theta_{\mathrm{ov}} \\ 0, & \theta_{\mathrm{on} 2}+\theta_{\mathrm{ov}} \leq \theta<\theta_{\mathrm{off} 2}\end{cases}
$$

where $\theta_{\text {on } 1}$ and $\theta_{\text {off } 1}$ are the first set of switching angles, and $\theta_{\text {on } 2}$ and $\theta_{\text {off } 2}$ are the second set of switching angles. By setting the size of $\theta_{\text {on2 }}$ and $\theta_{\text {off } 2}$ reasonably, it makes the $H$ phase on when the A-phase is on at the same time. The TSF is made to have a constant sum of 1 at any point in time, and the ratio of the maximum torque in the first positive torque region to the maximum torque in the second positive torque region is about $4: 1$ when the current is $10 \mathrm{~A}$. Therefore, a coefficient of 0.8 is added in the interval $\left[\theta_{\text {on } 1}, \theta_{\text {off } 1}+\theta_{\text {ov }}\right]$, and a coefficient of 0.2 is added in the interval $\left[\left[\theta_{\text {on } 2}, \theta_{\text {off } 2}+\theta_{\text {ov }}\right]\right.$, as shown in equation (6). A schematic diagram of the waveform diagram is shown in Figure 8.

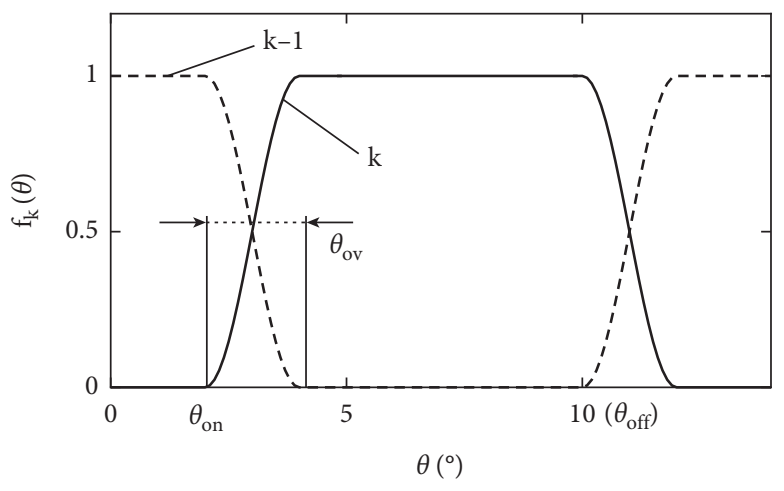

Figure 7: Cosine TSF waveform.

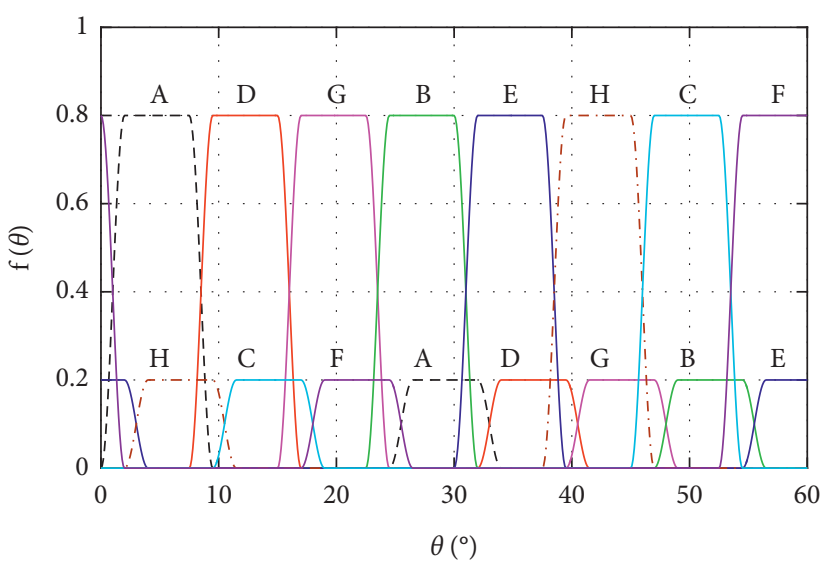

FIGURE 8: Waveform of improved TSF.

$$
f(\theta)= \begin{cases}0.8 f_{k}(\theta), & \theta_{\text {on } 1} \leq \theta \leq \theta_{\text {off } 1}+\theta_{\text {ov }} \\ 0.2 f_{k}(\theta), & \theta_{\text {on } 2} \leq \theta \leq \theta_{\text {off } 2}+\theta_{\text {ov }} \\ 0, & \text { else. }\end{cases}
$$

To meet the requirements, the motor winding method is optimized. The double windings are wound in the same direction on the same outer stator teeth, as shown in Figure 9. When $A$ and $H$ are on at the same time, the output torque increases due to the superposition of the magnetic fields. If the rotor rotates clockwise, the energizing sequence is $A(H) \longrightarrow D(C) \longrightarrow G(F) \longrightarrow B(A) \longrightarrow E(D) \longrightarrow H(G) \longrightarrow$ $C(B) \longrightarrow F(E)$, and if the rotor rotates counterclockwise, the energizing sequence is $A(H) \longrightarrow F(E) \longrightarrow C(B) \longrightarrow H$ $(G) \longrightarrow E(D) \longrightarrow B(A) \longrightarrow G(F) \longrightarrow D(E)$.

3.2. Design of Levitation Force Control System. DFC uses the levitation force as the control object and adds the closedloop buoyancy on the basis of the traditional square wave control to form a double closed-loop control. At the same time, the two-point levitation force regulator is adopted, as shown in Figure 10, to realize the high dynamics of motor rotor levitation control.

For hysteresis control of the levitation force, combined with Figure 10, taking $\mathrm{M}$-phase as an example, we assume that the rotor produces an eccentricity in the $-X$ direction, so the levitation force in the $+X$ direction needs to be 


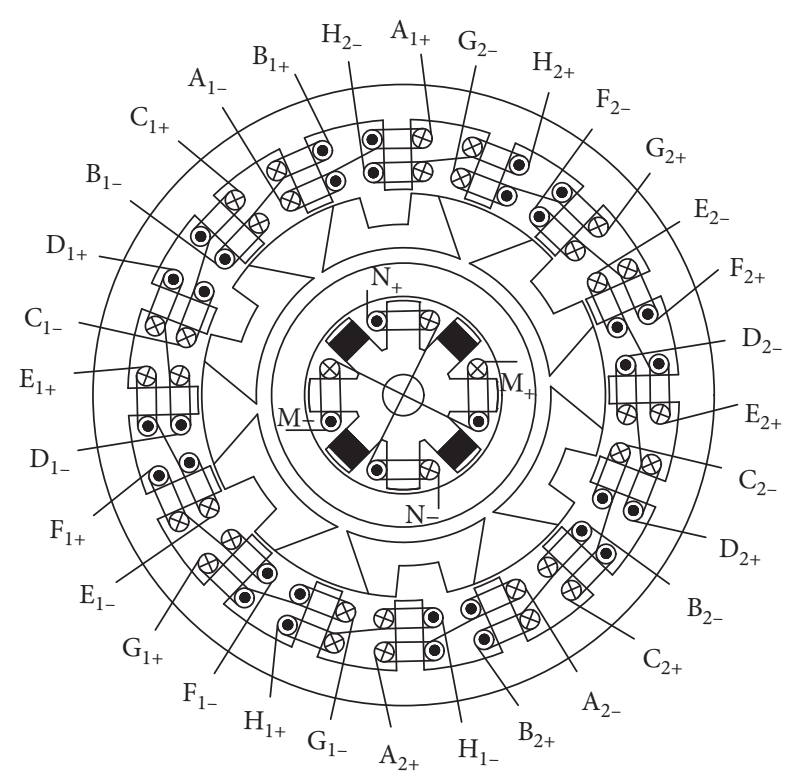

FIgURE 9: Winding optimization diagram.

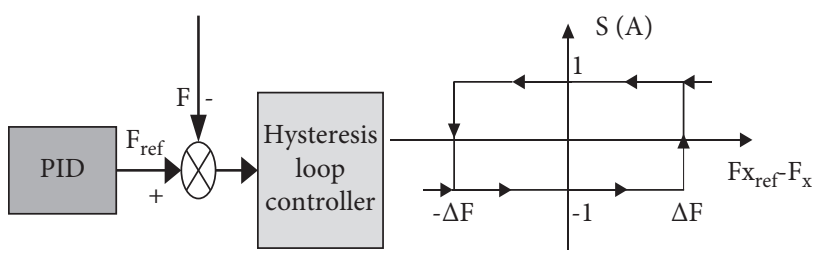

FIGURE 10: Levitation force control schematic.

increased. At this point, the actual levitation force $F$ is less than the reference levitation force $F_{\text {ref }}$, and the levitation force deviation is greater than the limit of the internal hysteresis loop $\Delta F\left(F_{\text {ref }}-F>\Delta \mathrm{F}\right)$. In order to increase the levitation force, a positive voltage should be applied across the winding $M$ to increase the current, and the voltage symbol " 1 " is chosen. The difference between $F x_{\text {ref }}$ and $F_{x}$ decreases as the current increases. Similarly when the actual levitation force $F$ is greater than the reference levitation force $F x_{\text {ref }}$, the levitation force deviation is greater than the internal hysteresis loop limit $\Delta F\left(F_{\text {ref }}-F>\Delta F\right)$. In order to reduce the levitation force, a negative voltage should be applied to the winding $M$ to increase the current; the voltage symbol " -1 " is selected. This creates a cycle to achieve stable control of the levitation forces. Similarly, the regulation of the levitation force in the $Y$ direction can be achieved by controlling the voltage sign of the levitation winding $N$, selected in the same way as in the $X$ direction.

\section{Control System Based on RBF Observer}

In the proposed control system, the torque and levitation forces are used as direct control objects, so the torque and levitation forces need to be estimated. From (1) and (2), the method ignores the magnetic saturation and leakage of the motor and is too complex to derive a torque model for the full angle [21]. The neural network observer is more effective and convenient than the mathematical model approach.
4.1. RBF Observer. Compared with other neural networks, RBF neural networks have the advantages of simple structure, good approximation and generalization ability, and fast learning speed. They are widely used in nonlinear control systems, and their structure is shown in Figure 11 [23]. There are three layers: input layer, hidden layer, and output layer, and there are no links between the same layers.

The input vector is $X=\left[x 1, x_{2}\right]^{T}$, the hidden layer is $H=\left[h_{1}, h_{2}, \ldots, h_{j}\right]^{T}$, the weight of the implied layer to the output layer is $W=\left[W_{1}, W_{2}, \ldots, W_{j}\right]^{T}$, and the output is $Y=W^{T} H$. The $h_{j}$ is the output of the $j$ neuron of the hidden layer, as shown in the following equation:

$$
h_{j}=\exp \left(-\frac{X-c_{j}}{2 b_{j}^{2}}\right),
$$

where $c_{j}$ is central vector and $b_{j}$ is the width of the Gaussian basis function. The relationship between phase current, rotor position angle, and torque, as shown in Figure 12(a), and the data relationship between levitation current, rotor eccentric displacement, and levitation force, as shown in Figure 13(a), were obtained by Maxwell simulation.

In the torque observer, the phase current and rotor position angle are used as inputs and the torque as output. The phase currents were taken in the range of 0-60 A, one value for every $2 \mathrm{~A}$; the rotor position angles were taken in the range of $0-60^{\circ}$, one value for every $2^{\circ}$, for a total of 900 samples; and the input quantities were normalized. The training results are shown in Figure 12(b). The levitation force observer takes levitation current and rotor eccentric displacement as input and levitation force as output. The levitation current takes values from 0 to $6 \mathrm{~A}$, one value for every $0.2 \mathrm{~A}$, and the eccentric displacement takes values from 0 to $0.4 \mathrm{~mm}$, one value for every $0.01 \mathrm{~mm} .1200$ training samples were taken, and the training results are shown in Figure 13(b). The smaller the target error, the higher the observation accuracy, but the longer the training time, the more the neurons. Therefore, in order to improve the training efficiency, the number of neurons is reduced while ensuring the training accuracy. After repeated training, the training target errors are determined as 0.0001 and 0.035 .

As shown in Figures 12(c) and 13(c), the simulation values of torque and levitation force are plotted against the training results. The errors are kept within $\pm 0.05 \mathrm{Nm}$ and $\pm 0.2 \mathrm{Nm}$, respectively. The training results are very close to the simulation values, and the errors are very small, achieving the observation of torque and levitation forces.

4.2. Control Block Diagram. According to the above analysis results, the control block diagram of $16 / 6 / 8$ DSBSRM is constructed as shown in Figure 14. The asymmetric halfbridge circuit is selected as the power converter with 8 phases for torque control and 4 phases for levitation force control.

In the torque control system, the required torque Tref $_{A} \sim$ Tref $_{H}$ can be obtained from the regulation of speed error by PID and TSF. Meanwhile, the actual torque value 


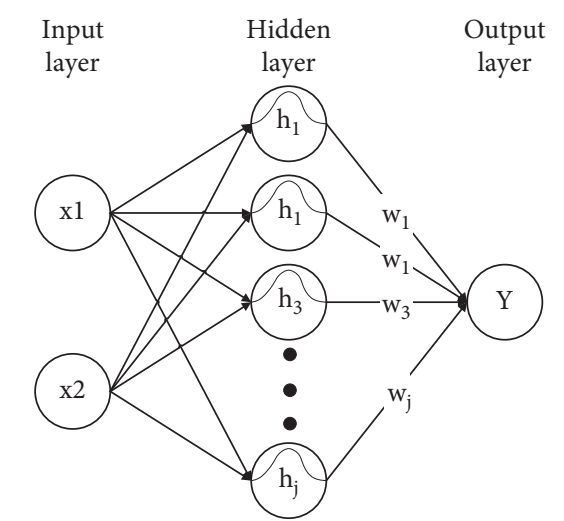

FIgURE 11: Structure of RBF neural network.

$\mathrm{TA} \sim \mathrm{TH}$ is obtained according to the RBF torque observer. $\operatorname{Tref}_{A} \sim \operatorname{Tref}_{H}$ and $T_{A} \sim T_{H}$ are converted into control signals by the hysteresis loop controller, which controls the on/off of the power converter to turn the torque winding on/off for stable rotation.

In the levitation control system, the required levitation forces $F x_{\text {ref }}, F y_{\text {ref }}$ are obtained from the regulation of displacement errors by the PID controller. At the same time, the actual levitation force values $F x, F y$ are obtained according to the RBF levitation force observer. $F x_{\text {ref }}, F y_{\text {ref }}$ and $F x, F y$ torque are converted into control signals by the hysteresis loop controller, which controls the on/off of the power converter to achieve stable levitation.

\section{Simulation Validation}

In order to verify the feasibility and effectiveness of the above control method, a 16/6/8 DSBSRM control simulation model is built based on MATLAB/Simulink simulation platform. $\quad n^{*}=600 \mathrm{rpm} ; \quad x^{*}=y^{*}=0 \mathrm{~mm} ; \quad \theta_{\text {on } 1}=2^{\circ}$; $\theta_{\text {off } 1}=10^{\circ} ; \theta_{\text {on } 2}=24^{\circ} ; \theta_{\text {off } 2}=31^{\circ} ; \theta_{\text {ov }}=2^{\circ} ;$ the load is $1.3 \mathrm{Nm}$.

Figures 15(a) and 15(b) show the speed waveforms of current square wave control, traditional DITC, and modified DITC. The $n^{*}$ increases to $1200 \mathrm{rpm}$ at $2 \mathrm{~s}$ and decreases to $600 \mathrm{rpm}$ at $5 \mathrm{~s}$. The speed reaches steady state at 0.23 and $2.54 \mathrm{~s}$ under current control and at $0.21 \mathrm{~s}$ and $2.31 \mathrm{~s}$ under traditional DITC, which is $8.6 \%$ and $42.6 \%$ improvement compared to the current control. The speed reaches steady state at $0.2 \mathrm{~s}$ and $2.22 \mathrm{~s}$ under the improved DITC. The improved DITC is a further shortening of the traditional DITC with improvement of $4.7 \%$ and $29 \%$. At low speeds, the overshoot of the improved DITC is greater than that of the conventional DITC, due to its higher output torque. However, at high speeds, the difference is not significant.

To research the output speed shaking and accuracy, Figures 15(c) and 15(d) show the amplification curves of the motor speed stabilized at $600 \mathrm{rpm}$ and $1200 \mathrm{rpm}$. Table 2 shows the comparison of speed fluctuation at $600 \mathrm{rpm}$ and $1200 \mathrm{rpm}$ for the three control methods.

As known from Table 2, at $600 \mathrm{rpm}$, the traditional DITC reduces the maximum speed error by $80 \%$ and the fluctuation amplitude by $73.8 \%$ compared to the current control.
Under the improved DITC, the error and speed fluctuation are further reduced based on the conventional DITC. The maximum speed error is reduced by $62.5 \%$ and the fluctuation amplitude is reduced by $45.5 \%$. At $1200 \mathrm{rpm}$, the improved DITC reduces the maximum speed error by $31.8 \%$ and the fluctuation amplitude by $33.3 \%$ compared with the current control. Analyzing Figures 15(c) and 15(d) and Table 2, we find that the improved DITC can further suppress speed shake and improve speed accuracy.

Figures 16(a) and 16(b) show the torque waveforms at $1200 \mathrm{rpm}$ for both control methods. Compared to the traditional DITC, the torque fluctuation peak is smaller under the improved DITC, which effectively reduces the torque fluctuation. At the same time, when the $A$-phase winding provides torque, the $H$-phase winding provides torque at the same time. The energization law of the winding is $A(H) \longrightarrow$ $D(C) \longrightarrow G(F) \longrightarrow B(A) \longrightarrow E(D) \longrightarrow H(G) \longrightarrow C(B) \longrightarrow F$ $(E)$, which is consistent with the theoretical analysis in Section 3.1.

Figure 17 shows the torque waveform curves under the three control methods. In Figure 17(a), steady-state torque ranges are $0.05-1.62 \mathrm{Nm}$ and $0.32-2.54 \mathrm{Nm}$, and pulsation amplitudes are $1.57 \mathrm{Nm}$ and $2.26 \mathrm{Nm}$ for $600 \mathrm{rpm}$ and $1200 \mathrm{rpm}$ under control. In Figure 17(b), steady-state torque ranges are $0.32-1.22 \mathrm{Nm}$ and $0.65-2.45 \mathrm{Nm}$ under traditional DITC, which reduces torque pulsations by $42.6 \%$ and $20.35 \%$ compared to current control. In Figure 17(c), steadystate torque ranges are $0.34-0.86 \mathrm{Nm}$ and $0.79-2.18 \mathrm{Nm}$ under the improved DITC. The torque pulsations of the improved DITC are reduced by $42.2 \%$ and $22.8 \%$ compared to the traditional DITC. Analyzing Figures 18(a) and 18(b), we find that the RBF torque observer has an observation error under the three control methods. With all three control methods, the observer can observe the torque values well and within a manageable margin of error. The torque fluctuation of the improved DITC is the smallest, so the error is the smallest and fluctuates within $\pm 0.02 \mathrm{Nm}$ in steady state. Analyzing Figures 17 and 18, we infer that the improved torque control system not only observes torque well, but also suppresses torque fluctuations well and improves the robustness of the motor.

Figure 19 shows the steady-state displacement waveforms in the $X$ direction controlled by current control and DFC. Under current control, the radial displacement of the rotor fluctuates at -0.107 to $0.139 \mathrm{~mm}$. The fluctuation amplitude is $0.248 \mathrm{~mm}$, and the maximum displacement error is $0.139 \mathrm{~mm}$. Under DFC, the radial displacement of the rotor fluctuates at $-0.035-0.044 \mathrm{~mm}$. The fluctuation amplitude is $0.079 \mathrm{~mm}$, and the maximum displacement error is $0.044 \mathrm{~mm}$. The radial displacement of the rotor was reduced by $68.1 \%$, and the maximum displacement error was reduced by $68.3 \%$. This shows that DFC can better suppress rotor jitter and improve levitation accuracy.

Figures 20(a) and 20(b) show the waveform of the levitation force in $X$ direction controlled by current control and DFC. The radial levitation force fluctuates at $-74-70 \mathrm{Nm}$ with a fluctuation of $144 \mathrm{Nm}$ under current control. Under DFC, the levitation force is within -22 to $34 \mathrm{Nm}$ with a fluctuation of $56 \mathrm{Nm}$. The radial levitation force fluctuation 


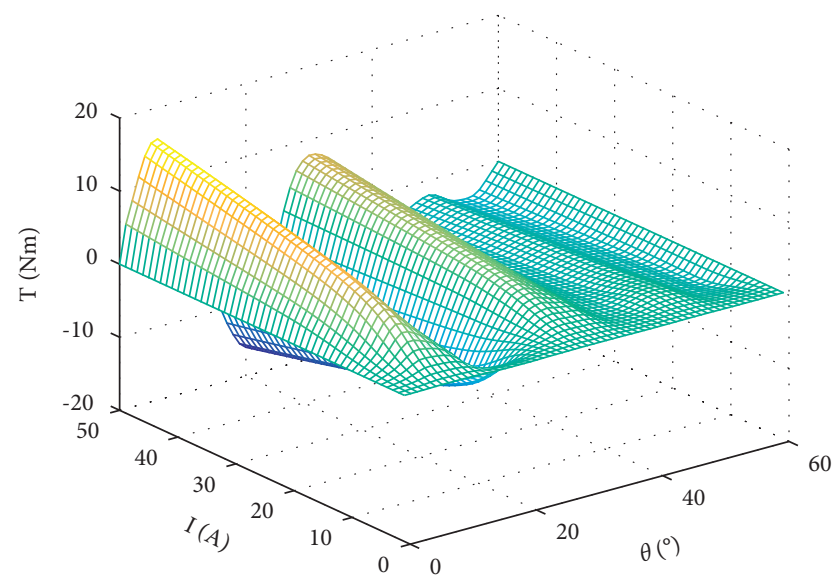

(a)

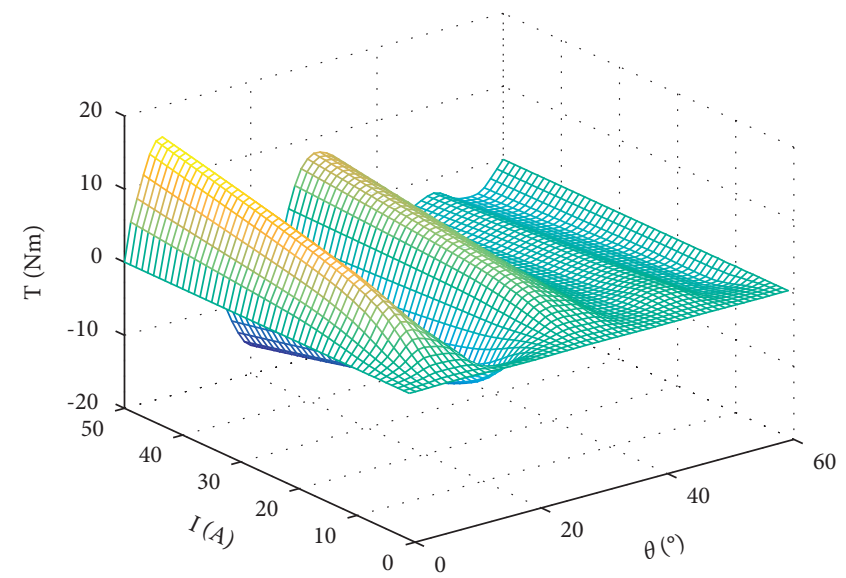

(b)

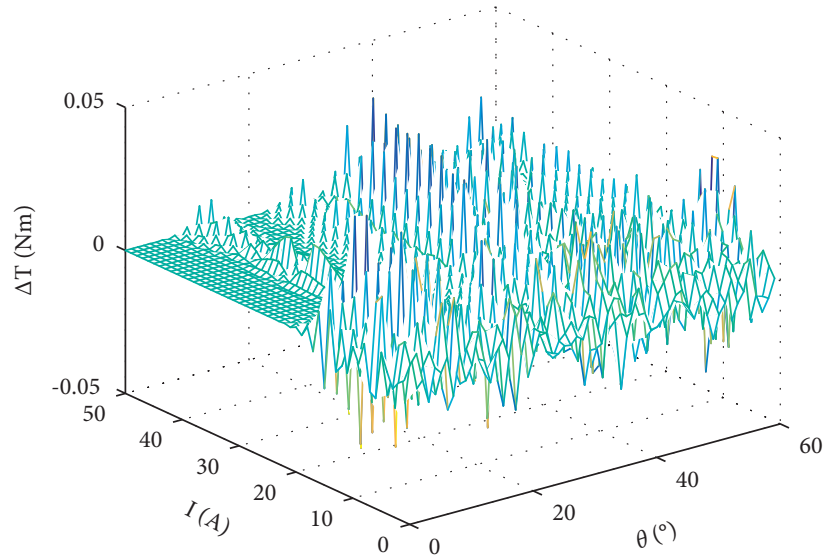

(c)

FIGURE 12: Torque RBF training results: (a) simulation torque value; (b) torque training result; (c) error of simulation value and training result.

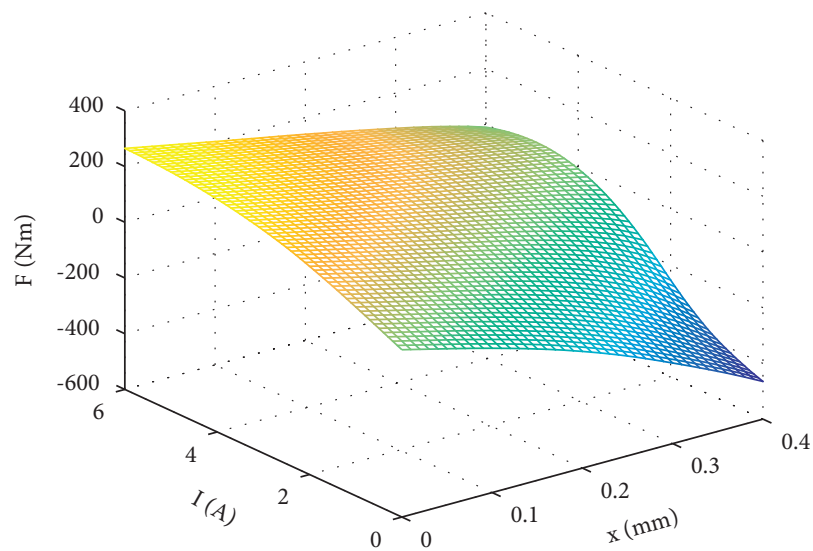

(a)

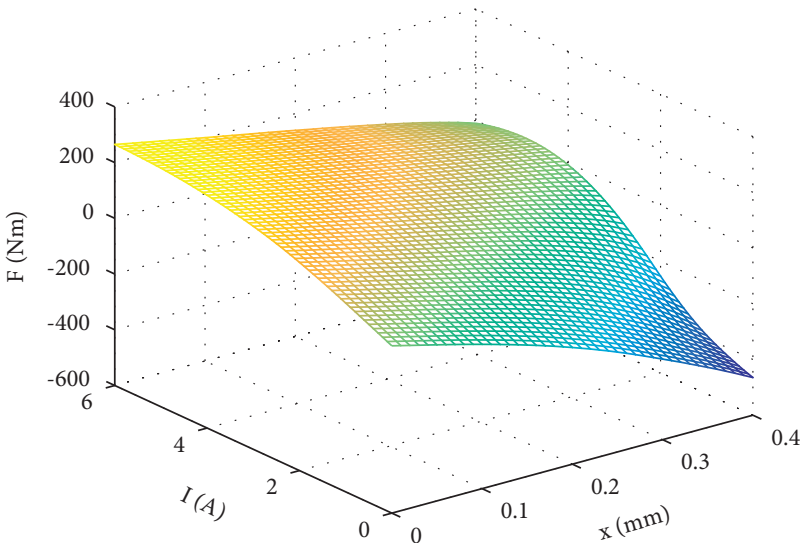

(b)

Figure 13: Continued. 


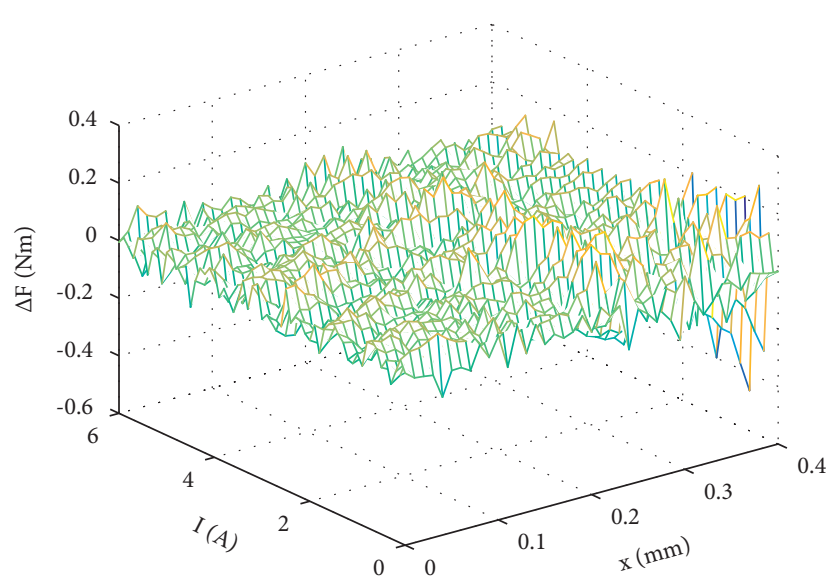

(c)

FIGURE 13: RBF training results of levitation force: (a) simulation levitation force value; (b) result of levitation force training; (c) error of simulation value and training result.

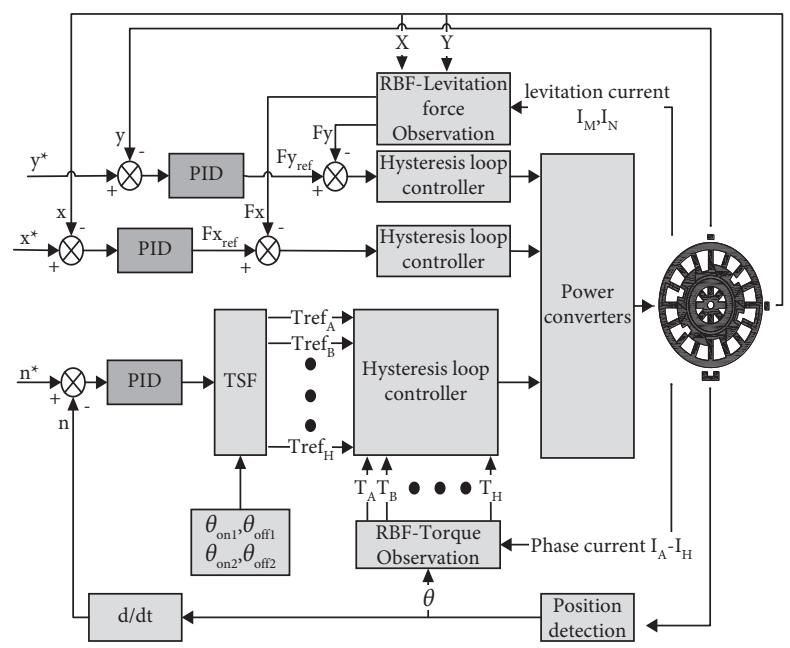

FIGURE 14: Control block diagram.
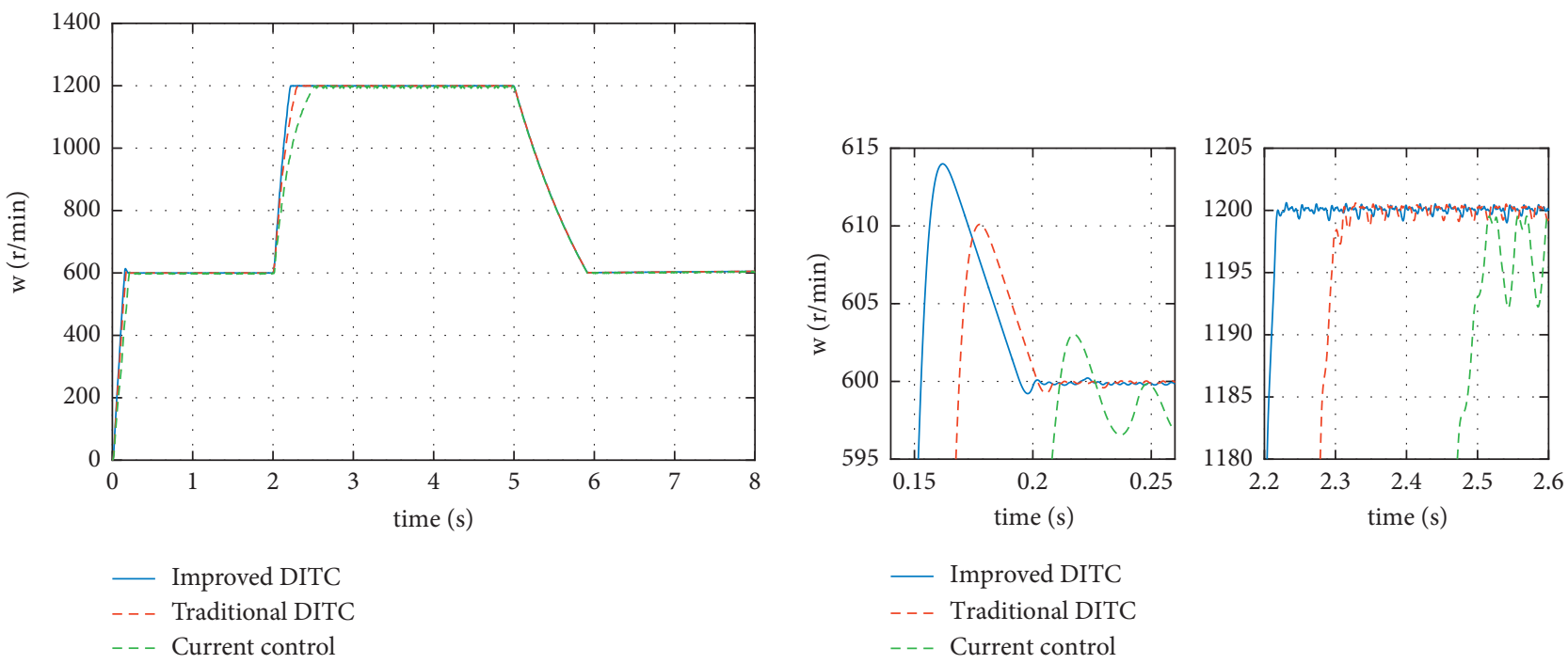

(a)

(b)

Figure 15: Continued. 


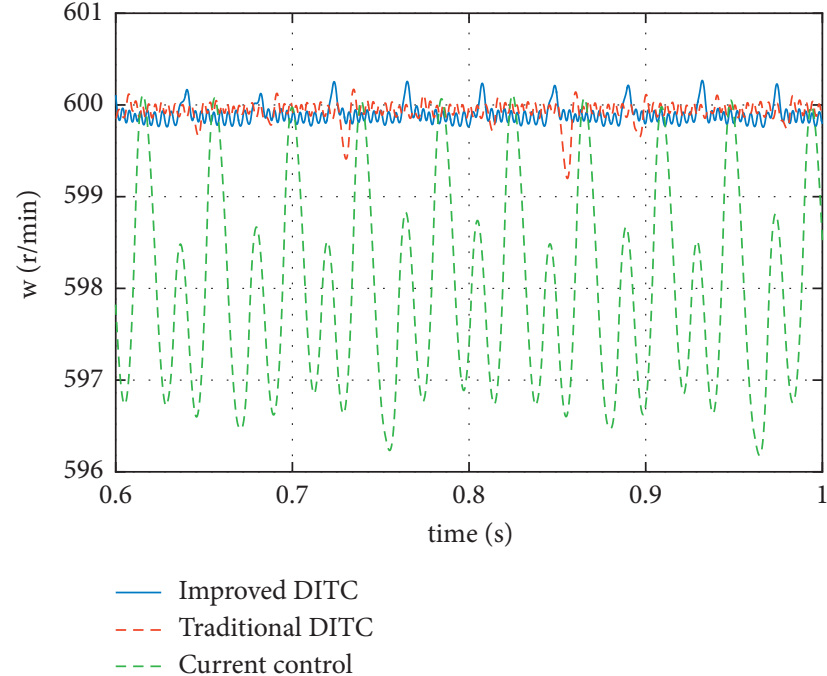

(c)

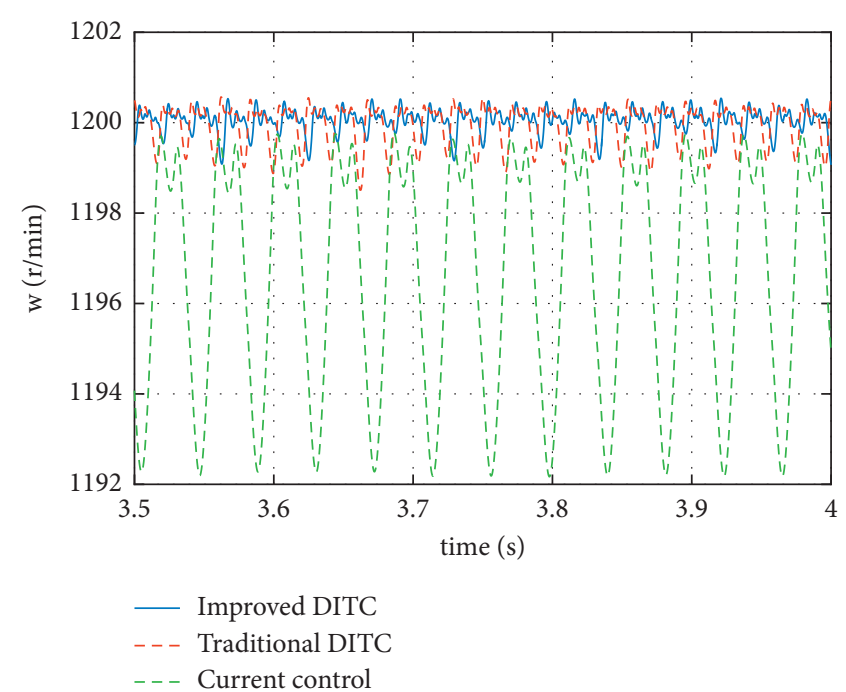

(d)

FIGURE 15: Dynamic response of speed: (a) speed change; (b) enlarged view of speed change; (c) steady speed of $600 \mathrm{rpm}$; (d) steady speed of $1200 \mathrm{rpm}$.

TABLE 2: Comparison of speed fluctuation.

\begin{tabular}{lccc}
\hline Speed $(\mathrm{r} / \mathrm{min})$ & Method & Wave range $(\mathrm{r} / \mathrm{min})$ & Maximum speed error $(\mathrm{r} / \mathrm{min})$ \\
\hline \multirow{4}{*}{600} & Current control & $596 \sim 600.2$ & 4 \\
& Traditional DITC & $599.2 \sim 600.3$ & 0.8 \\
\hline \multirow{3}{*}{1200} & Improved DITC & $599.7 \sim 600.3$ & 0.3 \\
& Current control & $1191.4 \sim 1199$ & 8.6 \\
& Traditional DITC & $1197.8 \sim 1199.9$ & 2.2 \\
& Improved DITC & $1198.5 \sim 1199.9$ & 1.5 \\
\hline
\end{tabular}

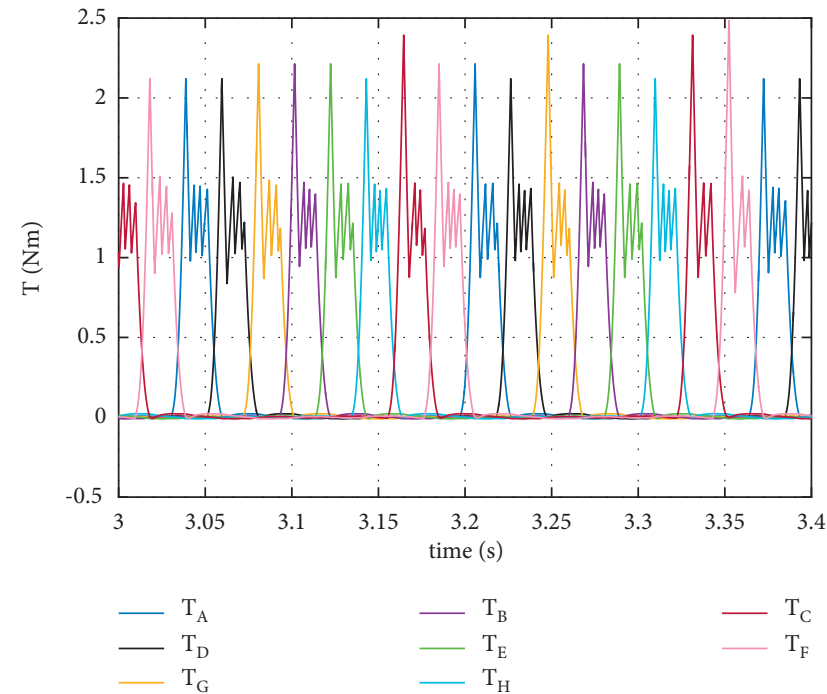

(a)

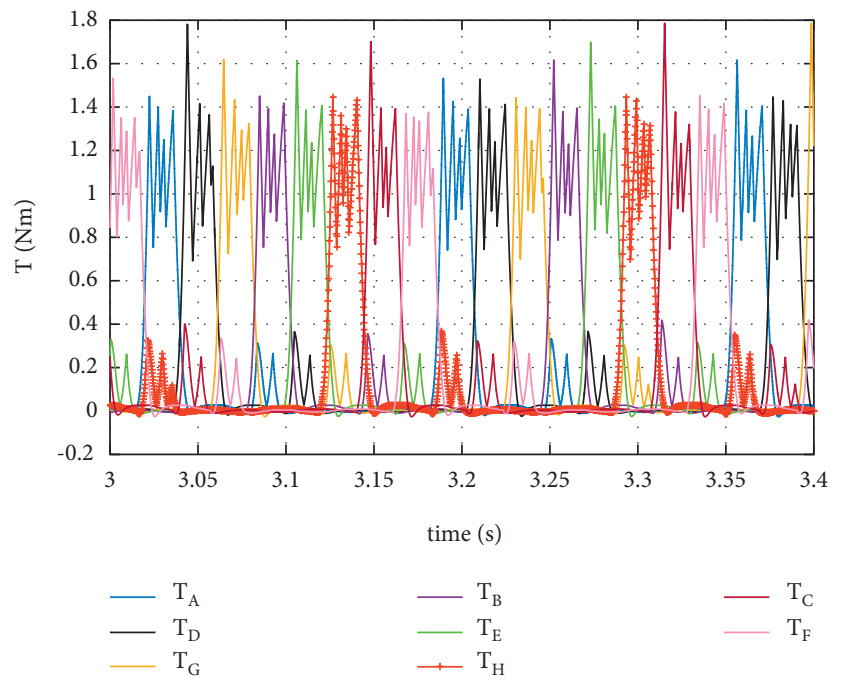

(b)

FIGURE 16: Various torque curves: (a) various torque curves of traditional DITC; (b) various torque curves of improved DITC.

of the rotor is reduced by $61.13 \%$. Analyzing Figure 21, we find that the RBF levitation force observers have an observation error under the two control methods. The levitation force under the DFC is smaller, so the observation error minimum is within $-0.1-0.4 \mathrm{Nm}$. Analyzing Figures 20 and 21, we conclude that the improved levitation force control system not only observes levitation force well, but also suppresses levitation force fluctuations. 


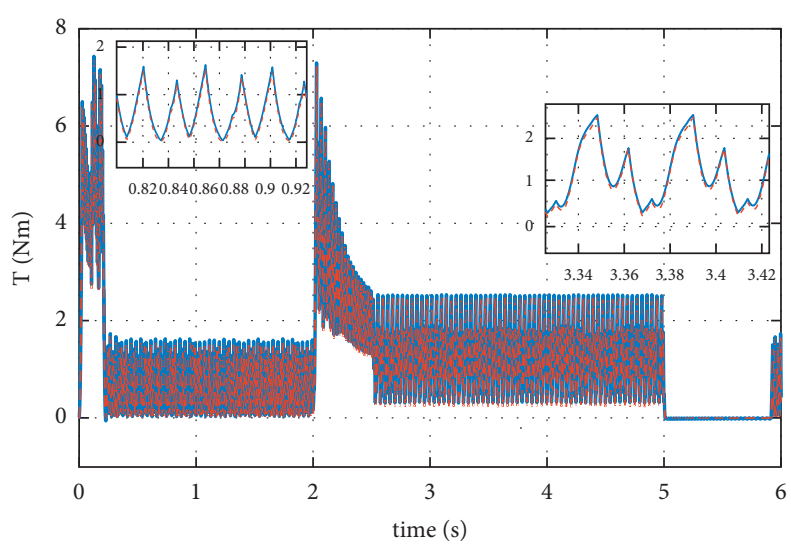

Current control - - - Torque observation

(a)

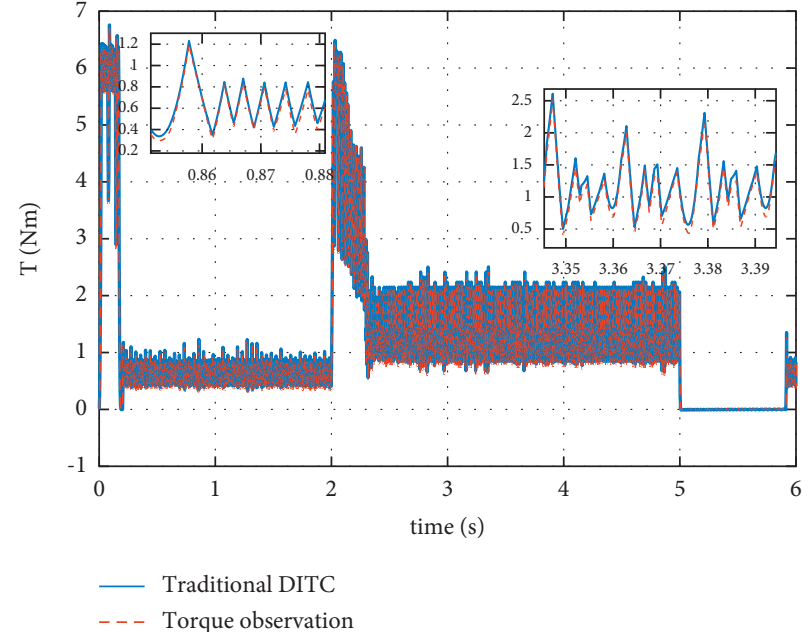

(b)

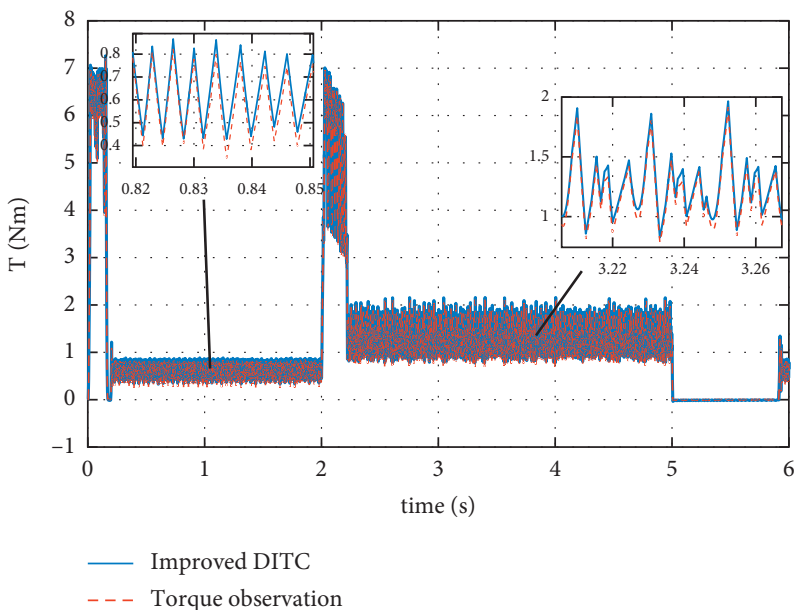

(c)

FIGURE 17: Torque ripple and observation: (a) current control; (b) traditional DITC; (c) improving the DITC.

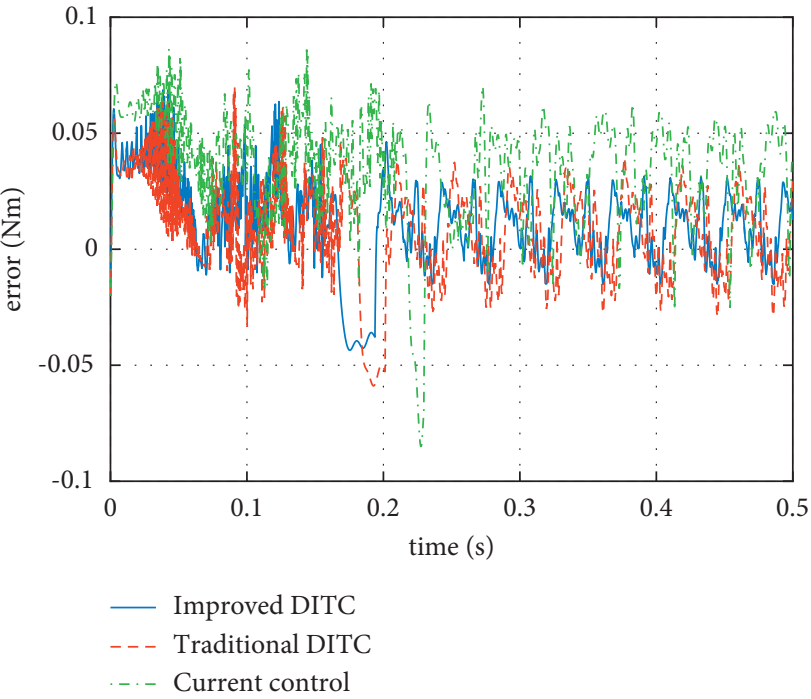

(a)

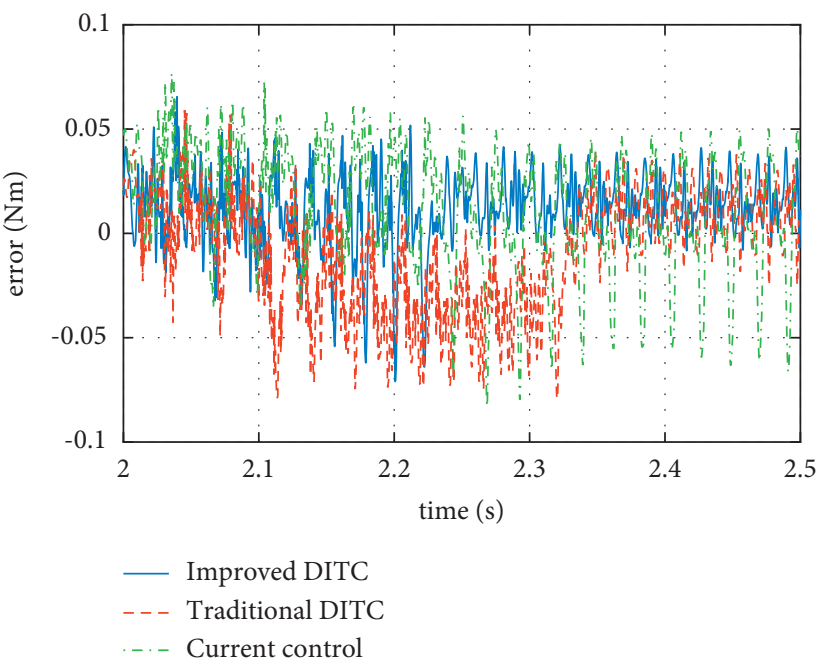

(b)

FIgURE 18: Torque observation error: (a) torque observation error at $600 \mathrm{rpm}$; (b) torque observation error at $1200 \mathrm{rpm}$. 


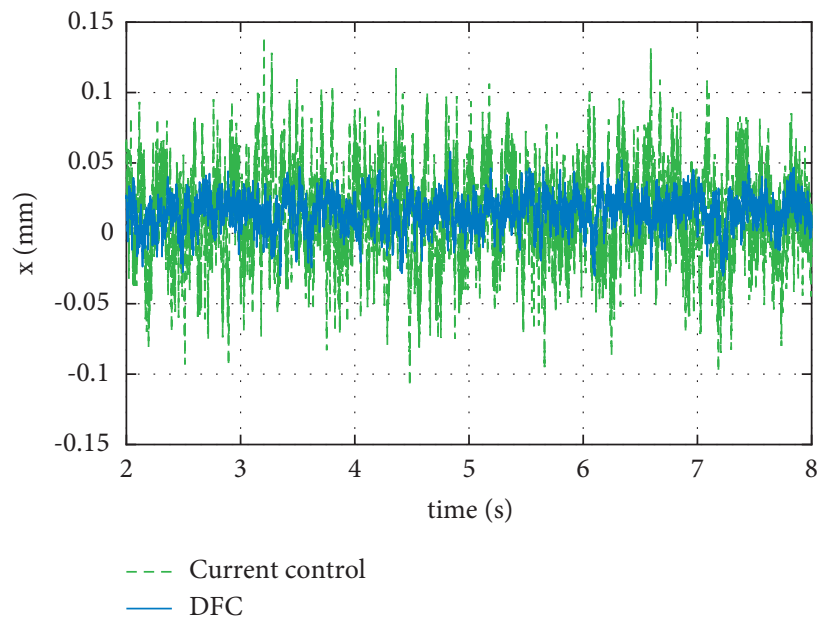

Figure 19: Rotor displacement in $X$ direction.

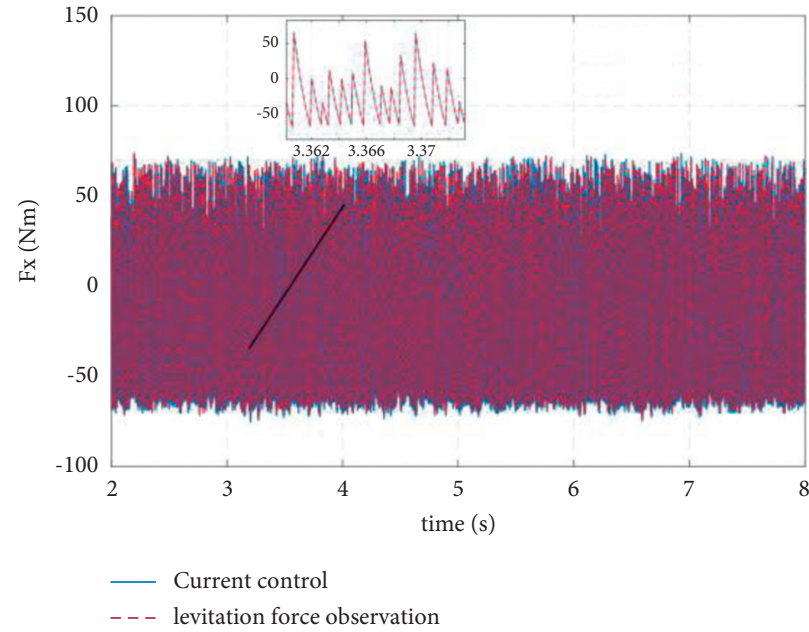

(a)

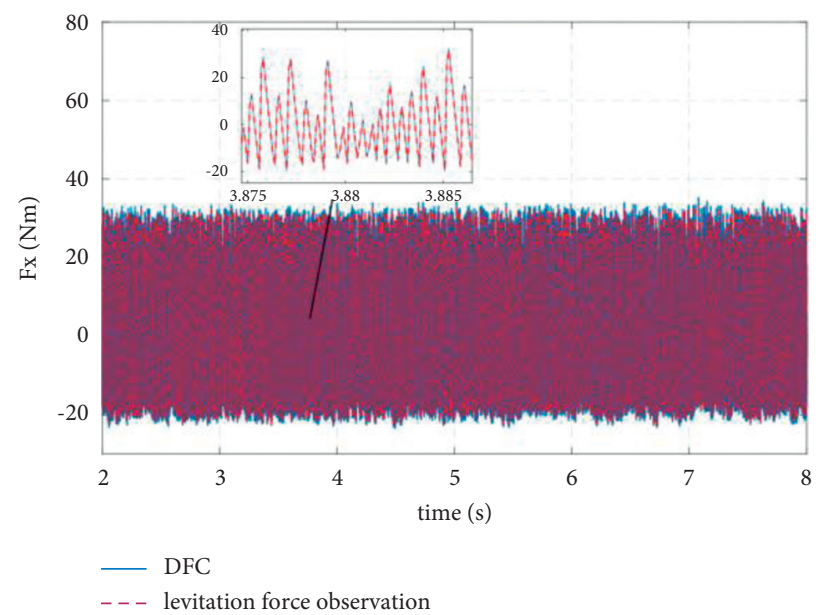

(b)

FIGURE 20: Levitation force ripple and observation: (a) current control; (b) DFC.

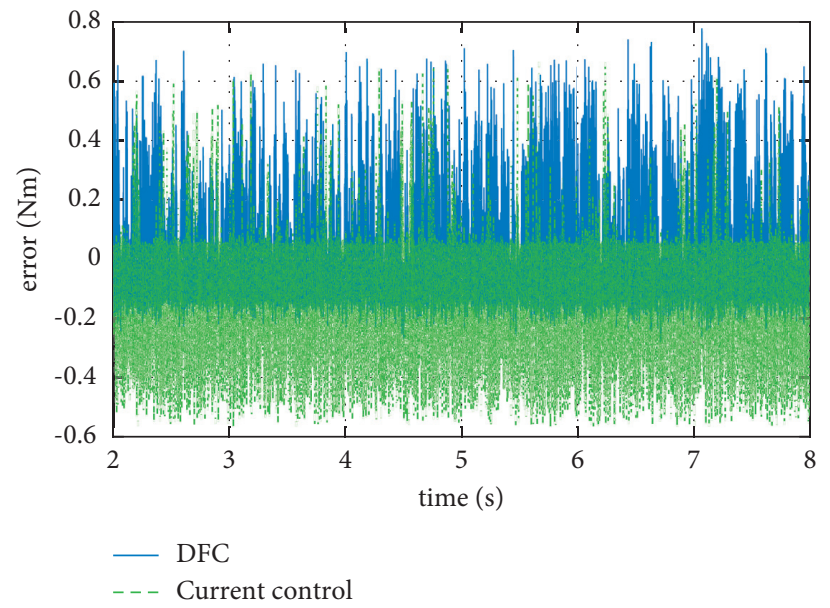

FIGURE 21: Levitation force observation error. 


\section{Conclusions}

This paper first analyzes the operating principle and decoupling effect of the $16 / 6 / 8$ DSBSRM, and the control system of DITC and DFC based on TSF is proposed. Meanwhile, RBF neural network is used to build a torque and levitation force observer to form a double closed-loop control. Then, torque ripple is reduced by optimizing the motor winding method and proposing a double switching angle DITC. Finally, the simulation is verified by the MATLAB/Simulink simulation platform. The results show that the control system not only is able to observe torque and levitation forces well, but also effectively suppresses speed jitter. At the same time, torque and levitation force ripples are reduced, and rotor radial displacement jitter is decreased. This increases the dynamic response time and robustness of the system.

\section{Nomenclature}

$A 1+, A 1-, A 2+$, and Four windings connected in series to A2-: form A-phase

$F_{A 1}$ and $F_{A 2}$ : Torque force generated by A-phase winding acting on rotor

$F 1, F 2, F 3$, and F4: Four permanent magnets generating levitation forces on the rotor

$+X$ direction and $X$-axis positive direction and $X$-axis

$-X$ direction: negative direction, respectively

$\Phi_{\mathrm{PM} 1}$ and $\Phi_{\mathrm{PM} 2}$ : The upper permanent magnet bias magnetic flux and the lower permanent magnet bias magnetic flux, respectively

$X-B$ and $Y-B$ : $\quad X$-axis positive flux density and $Y$-axis positive flux density, respectively

$\theta_{\text {on1 }}, \theta_{\text {off } 1}, \theta_{\text {on } 2}$, and The first set of switching angles and

$\theta_{\text {off } 2}$ : the second set of switching angles of the torque sharing function, respectively

$A(H)$ : When $A$-phase winding is on, $H$-phase winding is on at the same time

Tref $_{A} \sim$ Tref $_{H}$ : $\quad$ Reference torque of phase $A \sim H$ $\mathrm{T}_{A} \sim \mathrm{T}_{H}: \quad$ Actual torque of phase $A \sim H$

$F x_{\text {ref }}, F y_{\text {ref }}: \quad X$-axis reference levitation force and

$F_{x}, F_{y}:$

\section{Data Availability}

The data used to support the findings of this study are available from the corresponding author upon request.

\section{Conflicts of Interest}

The authors declare that they do not have any commercial or associative interest that represents conflicts of interest in connection with the work submitted.

\section{Acknowledgments}

This research was sponsored by Nature and Science Foundation of China (Project no. 51774193), Nature and Science Foundation of Shandong Province (Project no. ZR2019MEE068), Application Scientific Research of Qingdao City (Project no. 15-9-1-66-jch), and Postdoctoral Research Foundation of Qingdao City (Project no. 01020120521).

\section{References}

[1] M. Takemoto, K. Shimada, A. Chiba et al., "A design and characteristics of switched reluctance type bearingless motors," in Proceedings of the International Symposium on Magnetic Suspension Technology, pp. 49-63, Washington, DC, USA, September 1998.

[2] M. Takemoto, A. Chiba, and T. Fukao, "A new control method of bearingless switched reluctance motors using square-wave currents," in Proceedings of the Power Engineering Society Winter Meeting, pp. 375-380, Singapore, 2000.

[3] Y. K. Sun, Y. Yuan, Y. H. Huang, W. Y. Zhang et al., "A review of the development of magnetically levitated switched reluctance motors and their key technologies," Journal of Electrical Engineering Technology, vol. 30, no. 22, pp. 1-8, 2015.

[4] W. Amrhein, S. Silber, and K. Nenninger, "Developments on bearingless drive technology," in Proceedings of the 8th International Symposium Magnetic Bearings, pp. 229-234, Mito, Japan, August 2002.

[5] H. Wang and F. Li, "Design consideration and characteristic investigation of modular permanent magnet bearingless switched reluctance motor," IEEE Transactions on Industrial Electronics, vol. 67, no. 6, pp. 4326-4337, 2020.

[6] Y. Huang and F. Huang, "Design and analysis of a novel bearingless segmented switched reluctance motor," IEEE Access, vol. 7, pp. 94342-94349, 2019.

[7] Y. Yuan, Y. Sun, Q. Xiang, Y. Ren, and Q. Liu, "The study of switched reluctance motor for 4-DOF bearingless motor," Journal of Electrical Engineering \& Technology, vol. 14, no. 1, pp. 179-189, 2019.

[8] C. Sun, P. Zhuang, J. Li, and J. Li, "Design and analysis of a 16/ 6 bearingless switched reluctance motor with segment hybrid rotor teeth," IEEJ Transactions on Electrical and Electronic Engineering, vol. 15, no. 6, pp. 939-946, 2020.

[9] Z. Y. Zhu, Y. J. Jiang, J. Zhu, and X. Guo, "Performance comparison of $12 / 12$ pole with $8 / 10$ and $12 / 14$ pole bearingless switched reluctance machine," Electronics Letters, vol. 55, no. 6, pp. 327-329, 2019.

[10] Y. Sun, F. Yang, Y. Yuan, F. Yu, Q. Xiang, and Z. Zhu, "Analysis of a hybrid double stator bearingless switched reluctance motor," Electronics Letters, vol. 54, no. 24, pp. 1397-1399, 2018.

[11] X. Cao and C. Liu, "Decoupling mechanism and implementation of torque and levitation force in single-winding 12/ 4 bearingless switched reluctance motor," Transactions of China Electrotechnical Society, vol. 33, no. 15, 2018.

[12] W. Peng, F. Zhang, and J. W. Ahn, "Design and control of a novel bearingless SRM with double stator," in IEEE International Symposium onIndustrialElectronics, pp. 28-31, Hangzhou, China, May 2012.

[13] Y. Zhou, Y. Sun, and Z. Wang, "A double-stator magnetically levitated switched reluctance flywheel motor control system," 
Chinese Journal of Electrical Engineering, vol. 35, no. 21, pp. 5600-5606, 2015.

[14] Y. K. Sun, F. Y. Yu, Y. H. Huang, K. Zhang, and W. W. Lin, "Direct torque and direct levitation force control of dualstator magnetically levitated switched reluctance motor," Motor and Control Applications, vol. 45, no. 11, pp. 7-14, 2018.

[15] X. Cao, J. Zhou, C. Liu, and Z. Deng, "Advanced control method for single-winding bearingless switched reluctance motor to reduce torque ripple and radial displacement," IEEE Transactions on Energy Conversion, vol. 32, no. 4, pp. 15331543, 2016.

[16] X. Cao, Q. Sun, C. Liu, H. Zhou, and Z. Deng, "Direct control of torque and levitation force for dual-winding bearingless switched reluctance motor," Electric Power Systems Research, vol. 145, pp. 214-222, 2017.

[17] C. Li, G. Wang, Y. Li, and A. Xu, "Direct adaptive neural network control for switched reluctance motors with input saturation," IEEJ Transactions on Electrical and Electronic Engineering, vol. 13, no. 12, pp. 1804-1814, 2018.

[18] Y.-K. Sun, L. Wei, Y. Ye, H. Hong, and Y. Fan, "Direct torque control based on second order sliding mode for bearingless switched reluctance motor," Electric Machines and Control, vol. 22, no. 10, pp. 67-86, 2018.

[19] A. Xu, W. Zhang, and P. Ren, "Comparison of torque ripple reduction for switched reluctance motor based on DTC and DITC," IEEE Conference on Industrial Electronics and Applications, vol. 13, pp. 1727-1732, 2018.

[20] S. Wang, Z. Hu, and X. Cui, "Research on novel direct instantaneous torque control strategy for switched reluctance motor," IEEE Access, vol. p8, pp. p66910-66916, 2020.

[21] C. Sun, J. Li, H. Ding, H. Yang, S. Han, and N. Han, "Characteristic analysis of a new double stator bearingless switched reluctance motor," IEEE Access, vol. 9, pp. 3862638635, 2021.

[22] H. Hu, X. Cao, Y. Ning et al., "A new predictive torque control based torque sharing functionfor switched reluctance motors," in Proceedings of the 22nd International Conference on Electrical Machines and Systems, Harbin, China, August 2019.

[23] C. Li, G. Wang, Y. Fan, and L. Yan, Daptive RBF neural network controller design for SRM drives," in Proceedings of the Chinese Control Conference, pp. 6092-6097, Chengdu, China, July 2016. 